\title{
COMPLEX REGIONAL PAIN SYNDROME (CRPS) DIAGNOSIS : A CASE REPORT
}

\author{
Shahdevi Nandar Kurniawan ${ }^{1}$, Made Ayu Hariningsih Sunaga ${ }^{1}$, Sri Budhi Rianawati ${ }^{1}$, Masruroh Rahayu ${ }^{1}$ \\ ${ }^{I}$ Neurology Department, Medical Faculty, Brawijaya University, Saiful Anwar General Hospital, Malang, Indonesia. \\ Correspondence : shahdevinandar@ub.ac.id
}

\begin{abstract}
Complex regional pain syndrome (CRPS) is a term that describes a variety of chronic pain conditions that are believed to result from dysfunction in the central or peripheral nervous systems. Epidemiological data from 2 major studies show a CRPS incidence bet ween 5.5 and 26.2 cases per 100,000 people per year. A women, 35 years old came to the neurologic policlinic with complain of persistent pain in half left body since a year ago. Pain characteristic was pains and needles sensation, sometimes numbness, tingling that spreaded from left neck until left fingers.we found vasomotor, sensoric and motoric disorder that appropriated with budapest criteria. To diagnose CRPS need to holistic examination and deeper anamnesa to prevent wrong diagnosis. Pain treatment in this patient was not easy. She already has undergone 7 times epidural block and taken medicines nevertheless quality of pain decreased in small number with VAS score 7-8.
\end{abstract}

Keyword : Complex regional pain syndrome (CRPS), pain, diagnosis, treatment

\section{PENDAHULUAN}

Complex Regional Pain Syndrome (CRPS) merupakan sindrom yang berupa nyeri spontan maupun nyeri yang dicetuskan, timbul terus menerus, serta dirasakan pada regio tertentu dengan intensitas dan waktu yang disproporsional dibandingkan nyeri akibat trauma atau lesi pada umumnya. Nyeri yang dirasakan juga tidak sesuai dengan dermatom maupun teritori saraf tertentu. Selain itu, juga didapatkan keluhan pada distal dari saraf yang terganggu, berupa gangguan motorik, sensorik, sudomotor, edema vasomotor, dan gangguan tropik. Sindrom ini memiliki progresivitas yang bervariasi seiring berjalannya waktu. Ada 2 macam CRPS yaitu tipe 1 dan 2. CRPS tipe 1 didahului dengan jejas minor atau fraktur pada ekstremitas sebelumnya, sedangkan CRPS tipe 2 muncul setelah jejas mayor pada saraf tepi $(1,2)$.

Kejadian berbahaya, termasuk trauma minor (seperti sprains, memar, trauma jaringan lunak, frosbite atau lesi pada kulit), frktur tulang atau pembedahan yang melibatkan ekstremitas dapat menyebabkan CRPS I. Kadang-kadang ini terjadi setelah beberapa kejadian seperti trauma bahu, infark myocard atau lesi pada CNS. Gambaran klinis dari CRPS I meliputi abnormalitas dari sensoris, autonomik, tropik dan motorik dan adanya gejala inflamasi (3).

CRPS tipe II meluas ke arah distal ekstremitas diikuti dengan adanya trauma parsial pada lesi saraf perifer. Pada awal dideskripsikanya caulsagia, Weir Mitchell menjelaskan selain adanya nyeri spontan, pasien dilaporkan mengalami hipersensitivitas kulit terhadap stimulasi mekanis. Sehingga, pergerakan, suara keras atau emosi dapat memicu terjadinya nyeri.extremitas distal bengkak, perubahan warna kulit, akut atritis dapat muncul. Pada banyak kasus cenderung ditemukan ekstremitas yang terlibat lebih dingin dan berkeringat dibandingkan sisi yang tidak terlibat. Gangguan sensoris dan tropik dapat meluas melewati daerah inervasi saraf yang terlibat (4).

Diagnosa CRPS berdasarkan Orlando kriteria yang dikeluarkan oleh International Association for the Study of Pain lalu diperbaharui menjadi Budapest Criteria (panel), yang memiliki spesifisitas yang lebih tinggi dan juga ddimasukanya gejala motoris pada panel ini. Penelitian cohort internasional telah menkonfirmasi validitas dari Budapest criteria (5).

Diagnosa CRPS tidak bisa dibuat berdasarkan imaging atau tes laboraturium. (guidelines). Tetapi beberapa tes dapat dilakukan untuk menambahkan informasi dalam mengkonfirmasi adanya gangguan autonom, sensoris dan fungsi motorik (1).

Kurangnya pemahaman tentang patofisiologi dan kurangnya kriteria diagnosa objektif pada CRPS menyebabkan sulitnya menemukan modalitas terapi yang sesuai.

\section{Article History}

Received: 9 Februari 2020; Accepted: 11 Februari 2020; Published: 1 Maret 2020

Cite As:

Kurniawan SN, Sunaga MAH, Rianawati SB, Rahayu M. Complex Regional Pain Syndrome (CRPS) diagnosis : A case report. Journal of Pain, Vertigo and Headache; 2020.1: 1-3. 
Hanya sedikit regimen terapi yang berdasarkan evidencebased yang tersedia. Pengobatan CRPS memerlukan berbagai macam pendekatan, baik secara farmakologis maupun non farmakologis.Penegakan diagnosis harus dilakukan secara dini agar prognostik lebih baik. Pada keluhan ringan, kondisi dapat sembuh sempurna, sedangkan pada keluhan berat dan refrakter memerlukan pendekatan multidisipliner dari neurolog, anestesiolog, dokter ortopedi, fisioterapis, dan psikolog (6).

\section{KASUS}

Pada kasus ini dilaporkan wanita usia 35 tahun dengan keluhan nyeri setengah badan kiri yang sudah dirasakan sejak setahun yang lalu. Rasa nyeri seperti tersayat-sayat, rasa panas (+), kadang dirasa tebal. Ada rasa gringingingen pada leher menjalar sampai jari-jari sebelah kiri. Pada kaki kiri dirasakan nyeri dari pinggang kiri sampai lutut. Nyeri dirasa hilang timbul. Nyeri dipicu oleh aktifitas berat yang menggunakan tangan atau kaki kiri, saat berbaring kesisi kiri, saat menggerakan sendi tangan atau kaki kiri. jika dipakai istirahat berbaring ke sisi kanan nyeri sedikit berkurang. Nyeri tangan kiri dan kaki kiri tidak terjadi bersamaan. Awalnya yang dirasakan adalah nyeri pada pinggang kiri pada tahun 2009.keluhan nyeri leher kiri sampai jari-jari tangan kiri dirasakan 2 tahun kemudian. Nyeri leher dirasa meluas sampai setengah wajah bagian kiri, sampai kaki bagian kiri.riw nyeri diperberat dengan batuk (-) 8 Bulan yang lalu suhu tubuh tangan kiri dirasakan pasien sering lebih panas dibanding tangan sebelah kanan, tetapi akhir-akhir ini kadang dirasa sisi kiri lebih dingin dari sisi kanan.

Riwayat kaki kiri dan tangan kiri bengkak (+), bengkak hilang dengan sendirinya, warna kulit pada tangan kiri dan kaki kiri kemerah-merahan (+) tangan kiri dan kaki kiri jika berkeringat berbeda dengan sisi kanan, setengah badan kiri tidak mengeluarkan keringat. Kuku pada jari tangan kiri lebih rapuh dari pada tangan kanan $(+)$ kulit pada tangan kiri dan kaki kiri kering seperti lilin (+) sendi lutut dan leher sering terasa kaku dan nyeri jika digerakan. Kaki kiri dan tangan kiri dirasa lebih lemah daripada tangan dan kaki kanan.

\section{DISKUSI}

Pada pasien ini didapatkan tanda-tanda sindroma nyeri yang memenuhi kriteria Budapest sebagai suatu complex regional pain syndrome. Dimana pada pasien ini didapatkan nyeri yang terus menerus. Adanya rasa nyeri yang seharusnya tidak menimbulkan nyeri seperti saat pasien berbaring sisi kiri pasien merasakan nyeri pada badan sisi kiri, saat disentuh seharunya tidak nyeri tetapi pasien merasa nyeri sehingga pada pasien ini didapatkan alodinia. Nyeri ini tidak sesuai dengan dermatom. Awalnya dirasakan pada leher bagian kiri yang meluas ke arah distal dan juga ke wajah sebelah kiri. Dari pemeriksaan sensoris raba halus didapatkan alodinia. Didapatkan riwayat 8 bulan yang lalu sisi tubuh sebelah kiri dirasakan lebih panas dibanding sisi kanan. Tetapi belakangan terakhir dirasakan lebih dingin dan adanya warna kemerah-merahan pada tangan dan kaki kiri serta pada wajah kiri. Hal ini memenuhi kriteria vasomotor pada budapest kriteria.

Didapatkan pula keluhan edema pada kaki kiri dan tangan kiri. Badan sisi kiri tidak berkeringat dibanding sisi sebelah kanan. Hal ini memenuhi adanya gangguan sudomotor. Didapatkan pula kekeringan kulit yang tampak mengkilat pada sisi kiri dibandingkan sisi kanan. Kuku pasien sebelah kiri mudah rapuh dan pertumbuhan kuku tidak wajar tampak pada pemeriksaan fisik. Didapatkan kelemahan otot pada tangan kiri dan kaki kiri. Hal ini memenuhi kriteriaadanya gangguan motor/tropik.

Table 1. Kriteria diagnostik CRPS Budapest (1)

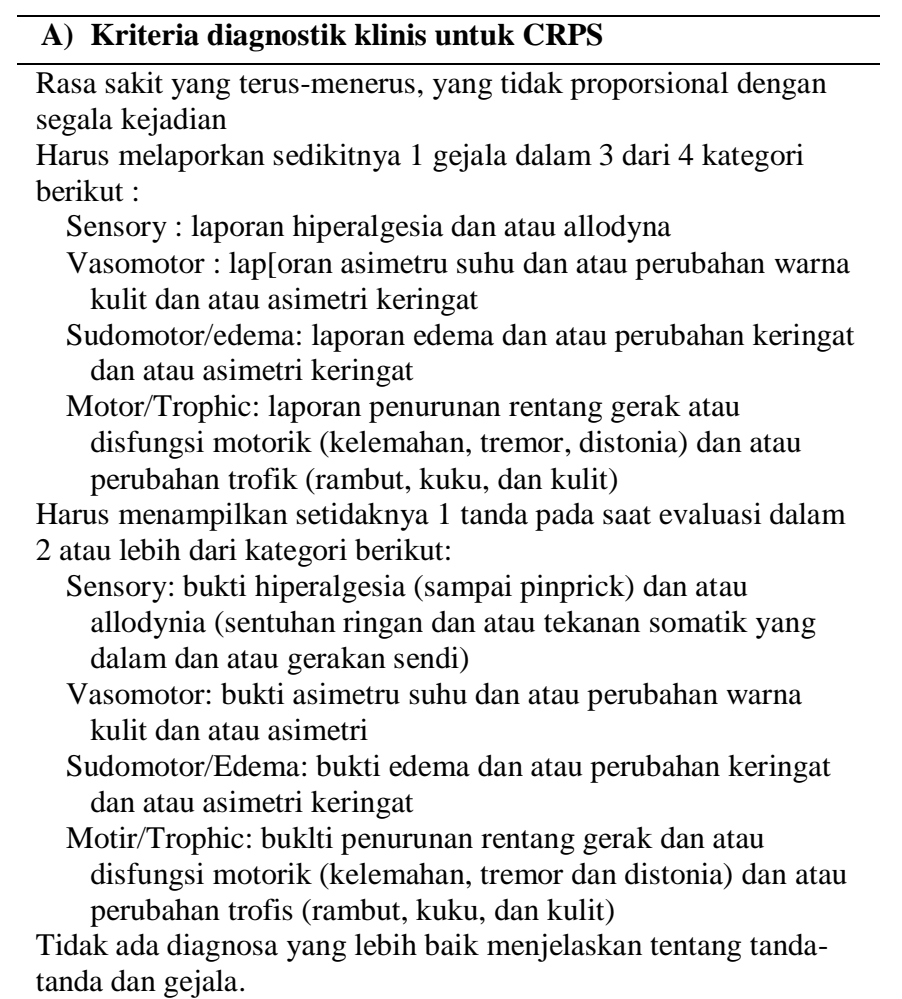

\section{B) Kriteria penelitian diagnostik untuk CRPS}

Berbeda dengan kalimat di atas "harus melaporkan setidaknya 1 gejala di masing-masing dari 4 kategori"

Kriteria diagnostik tidak sempurna; sensitivitas dan spesifisitas untuk diferensiasi terhadap gangguan nyeri neuropatik yang mudah dibedakan adalah 0,99 resp. 0,68 (spesifisitas) untuk kriteria klinis dan 0,78 resp. 0,79 CRPS, sindrom nyeri regional kompleks

Table 2. Tingkat keparahan skor CRPS CSS (1)

\begin{tabular}{l}
\hline Gejala yang dilaporkan sendiri \\
\hline Disproportionate pain yang berkelanjutan \\
Allodynia atau hyperalgesia \\
Asimetri Suhu \\
Asimetri warna kulit \\
Asimetri keringat \\
Edema asimetris \\
Perubahan trophic \\
Perubahan motor \\
\hline Tanda-tanda yang diamati pada pemeriksaan \\
\hline Hyperalgesia sampai pinprick \\
Allodynia \\
Asimetru suhu \\
Asimetri warna kulit \\
Asimetri keringat \\
Edema Asimetris \\
Perubahan trophic \\
Perubahan motor
\end{tabular}

Skor CSS maksimal adalah 16. Setiap gejala dan tanda dihitung dengan skor 1. CSS, skor keparahan CRPS 
Table 3. Perbandingan fitur klinis yang dipilih dalam definisi yang berbeda dari Complex Regional Pain Syndrome (CRPS)

\begin{tabular}{|c|c|c|c|c|}
\hline Terminologi CRPS & $\begin{array}{c}\text { CRPS tipe 1 } \\
\text { Orlando } 1994\end{array}$ & $\begin{array}{c}\text { CRPS tipe } 2 \\
\text { Orlando } 1994\end{array}$ & $\begin{array}{l}\text { CRPS Bruehl } \\
1998\end{array}$ & $\begin{array}{l}\text { CRPS Budapest } \\
2003\end{array}$ \\
\hline Pemicu fisik (saraf type 2) & \pm & $\sqrt{ }$ & & \\
\hline Disproportionate pain, allodynia atau hyperalgesia & $\sqrt{1}$ & $\sqrt{ }$ & & \\
\hline Disproportionate pain & & & $\sqrt{ }$ & $\sqrt{ }$ \\
\hline $\begin{array}{l}\text { Tanda : } \\
\text { swelling/vasomotor/sudomotor/edema/motor/thropic }\end{array}$ & $\sqrt{ }$ & $\sqrt{ }$ & & \\
\hline Gejala : sensory/vasomotor/sudomotor/edema & & & 4 of 4 & $\geq 3$ of 4 \\
\hline Tanda: sensory/vasomotor/sudomotor/edema & & & $\geq 1$ in $\geq 2$ & $\geq 2$ of 4 \\
\hline Tidak termasuk patologi penjelas & $\sqrt{ }$ & $\sqrt{ }$ & $\sqrt{-2}$ & $\sqrt{ }$ \\
\hline Sensitifitas & 0.99 & & & 0.85 \\
\hline Specificity & 0.68 & & & 0.69 \\
\hline
\end{tabular}

e $=$ ada $\pm=$ bisa ada bisa tidak

Dari empat kategori gejala pasien ini memenuhi keempat katagori dan saat datang ke poli klinik ada dua kriteria yang masih tampak yaitu alodinia dan adanya motor/tropik (kelemahan ekstremitas sisi kiri, kulit yang kering seperti lilin pada sisi kiri dan pertumbuhan kuku yang tidak normal). Sehingga pasien ini memenuhi kriteria diagnosa CRPS. Lalu dilakukan pemeriksaan MRI cervical dan lumbal. Didapatk adanya HNP pada servical dan lumbosacral. Pasien dirujuk ke poli ortopedia. Pada pasien ini didapatkan hasil EMG berupa mild compression pada saraf servical sehingga pada pasien ini didaptakan CRPS tipe 2. pasien dan pada pasien juga idak dilakukan analisa genetika.

Terapi yang diberikan pada pasien ini awalnya amitriptilin dengan dosis $10 \mathrm{mg}$ dengan diazepam $0.5 \mathrm{mg}$ selama satu bulan. Menurut pasien ada sedikit perbaikan nyeri yaitu 30 $\%$. Berdasarkan literatur Antidepresan trisiklik (TCA) adalah agen yang paling baik dalam mengatasi nyeri neuropatik. Secara umum, TCA bekerja untuk mencegah reuptake transmiter monoaminergik. TCA juga memiliki efek analgesik dan memiliki efek dalam memperbaiki tidur, kecemasan, dan kualitas mood. Dosis yang diperlukan untuk mengurangi nyeri adalah $75-150 \mathrm{mg} /$ hari, lebih rendah dari dosis yang dibutuhkan untuk mencapai efek anti depresan. Efek analgesik didapatkan setelah 1-2 minggu dengan puncak pada 4-6 minggu. Belum didapatkan penelitian penggunaan TCA pada CRPS. 1 dosis yang diberikan pada pasien ini belum maksimal tetapi dari subyektif yang dirasakan pasien ada sedikit perbaikan dengan nyerinya.

Lalu terapi pasien dirubah dengan mengunakan Gabapentin dengan dosis 1x300 mg. Pada literatur antikolvusan gabapentin pernah digunakan sebagai analgesik pada pasien CRPS dan didapatkan analgesik efek. Setelah penggunaan gabapentin selama 3 minggu pasien mengatakan dibanding sebelumnya nyeri ada perbaikan dari skor 1-10 yang awalnya 9-10 saat ini didapatkan skor 8.

Pasien ini direncanakan untuk dikirim ke rehabilitasi medik untuk fisioterapi tetapi pasien menolak. Terapi psikologis pada pasien ini belum dilakukan. Tetapi pasien telah dijelaskan tentang penyakitnya. Dimana CRPS ini bukanlah penyakit yang mudah untuk mengurangi rasa nyerinya. Sehingga diharapkan pasien tidak menganggap nyeri dapat hilang setelah minum obat-obatan dan dapat lebih realistik terhadap penyakitnya saat ini.

\section{KESIMPULAN}

Penegakan diagnosis CRPS dilakukan secara klinis dengan mengeksklusi kelainan lainnya. Salah satu kriteria yang dipakai adalah kriteria Budapest. Tidak ada pemeriksaan standar untuk memastikan diagnosis CRPS. Gejala dan tanda klinis yang ada pada CRPS adalah nyeri, gangguan sensoris, gangguan. Pada pasien ini memenuhi kriteria Budapest dan digolongkan sebagai CRPS tipe II karena didapatkan lesi saraf servical. Prognosa pasien tidak baik. Manajemen nyeri pada CRPS tidaklah mudah pada pasien ini. Pemberian injeksi epidural sudah dilakukan total sebanyak 7 kali, dan dengan terapi oral didapatkan sedikit perbaikan dan pasien masih menolak untuk fisioterapi.

\section{DAFTAR PUSTAKA}

1. Birklein F, Dimova V. Complex regional pain syndrome-up-todate. PAIN Reports [Internet]. 2017 Nov 1 [cited 2020 Feb 9];2(6):e624. Available from: http://insights.ovid.com/crossref?an=01938936-20171200000008

2. Beck RW. Conservative therapy for Complex Regional Pain Syndrome Type I in a paediatric patient: a case study. J Can Chiropr Assoc [Internet]. 2009 [cited 2020 Feb 9];53(2):95-101. Available http://www.ncbi.nlm.nih.gov/pubmed/19506699

from

3. Ratti C, Nordio A, Resmini G, Murena L. Post-traumatic complex regional pain syndrome: Clinical features and epidemiology. Vol. 12, Clinical Cases in Mineral and Bone Metabolism. CIC Edizioni Internazionali s.r.l.; 2015. p. 11-6.

4. Sebastin SJ. Complex regional pain syndrome. Vol. 44, Indian Journal of Plastic Surgery. Thieme Medical Publishers; 2011. p. 298-307.

5. Marinus J, Moseley GL, Birklein F, Baron R, Maih??fner C, Kingery WS, et al. Clinical features and pathophysiology of complex regional pain syndrome. Lancet Neurol. 2011;10(7):637-48.

6. Mackey S, Feinberg S. Pharmacologic therapies for complex regional pain syndrome. Vol. 11, Current Pain and Headache Reports. NIH Public Access; 2007. p. 38-43.

7. Dutton K, Littlejohn G. Terminology, criteria, and definitions in complex regional pain syndrome: Challenges and solutions. Vol. 8, Journal of Pain Research. Dove Medical Press Ltd.; 2015. p. $871-7$ 